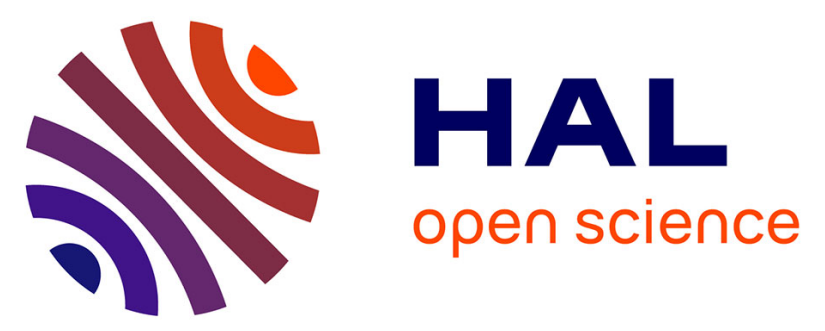

\title{
Recovery of primary sporocysts in vivo in the Schistosoma mansoni/Biomphalaria glabrata model using a simple fixation method suitable for extraction of genomic DNA and RNA. \\ Jean-François Allienne, André Théron, Benjamin Gourbal
}

\section{To cite this version:}

Jean-François Allienne, André Théron, Benjamin Gourbal. Recovery of primary sporocysts in vivo in the Schistosoma mansoni/Biomphalaria glabrata model using a simple fixation method suitable for extraction of genomic DNA and RNA.. Experimental Parasitology, 2011, 129 (1), pp.11-16. 10.1016/j.exppara.2011.06.003 . halsde-00612896

\section{HAL Id: halsde-00612896 \\ https://hal.science/halsde-00612896}

Submitted on 2 Feb 2012

HAL is a multi-disciplinary open access archive for the deposit and dissemination of scientific research documents, whether they are published or not. The documents may come from teaching and research institutions in France or abroad, or from public or private research centers.
L'archive ouverte pluridisciplinaire HAL, est destinée au dépôt et à la diffusion de documents scientifiques de niveau recherche, publiés ou non, émanant des établissements d'enseignement et de recherche français ou étrangers, des laboratoires publics ou privés. 
1 Recovery of primary sporocysts in vivo in the Schistosoma mansoni / Biomphalaria

2 glabrata model using a simple fixation method suitable for extraction of genomic DNA 3 and RNA.

4

5

6 Jean-François Allienne ${ }^{1,2}$, André Théron ${ }^{1,2}$ and Benjamin Gourbal ${ }^{1,2, *}$

7

$8{ }^{1}$ CNRS, UMR 5244, Ecologie et Evolution des Interactions (2EI), Perpignan, F-66860,

9 France

10

${ }^{2}$ Université de Perpignan Via Domitia, Perpignan, F-66860, France

*Corresponding author: Benjamin Gourbal

Centre de Biologie et d'Ecologie Tropicale et Méditerranéenne

17 Ecologie et Evolution des Interactions UMR 5244, CNRS, Université de Perpignan

1852 Ave Paul Alduy, 66860 Perpignan Cedex, France.

19 Phone: 33 (0)4 30192312

$20 \quad$ Fax: $33(0) 468662281$

21 E-mail: benjamin.gourbal@univ-perp.fr 


\section{Abstract}

24 Detailed studies of host/parasite interactions are currently limited because in-situ gene sequencing or monitoring of parasite gene expression is so far limited to genes presenting a high loci copy number in the Schistosome genome or a high level of expression. Indeed, how to investigate the host parasite molecular interplay when parasites are not directly accessible 28 in vivo? Here we describe a method to circumvent this problem and to analyze DNA and 29 RNA of Schistosoma mansoni during the interaction with its intermediate snail host Biomphalaria glabrata. We propose a technique for improved DNA and RNA extraction

31 from the intra-molluscan stage of the parasite recovered after fixation of infected snails in Raillet-Henry solution. The extractions can be used for genetic analysis, transcription studies and microsatellite genotyping.

34

35 Keywords: Schistosoma mansoni, Biomphalaria glabrata, intramolluscan stage, DNA/RNA extraction. 


\section{Introduction}

Schistosomiasis or bilharzia is a tropical parasitic disease affecting 200 million humans in 74 countries, causing 200,000 deaths annually (WHO, 2002). It is the second most important tropical disease in terms of morbidity after malaria. Schistosomiasis is caused by flatworms of the genus Schistosoma (Plathyhelminth, Digenea) (Chitsulo, et al., 2004, Gryseels, et al., 2006). The cycle of the parasite is complex. It requires humans as definitive hosts and freshwater snail species as intermediate hosts. Infection occurs in water by the free-living larval stages (cercaria for the definitive host and miracidia for the intermediate host). Significant attention has been paid to freshwater snails in the past because of both their medical and epidemiological importance as intermediate hosts for schistosome parasites. Moreover, the interaction between Schistosoma mansoni and the snail Biomphalaria glabrata provides a model of choice in evolutionary biology to investigate the host-parasite coevolutionary dynamics but also invertebrate immune response (Baeza Garcia, et al., 2010, Lockyer, et al., 2008, Mone, et al., 2010, Roger, et al., 2008). While snail response to infection can be readily studied particularly at the molecular level (Adema, et al., 2010, Baeza Garcia, et al., 2010, Guillou, et al., 2007, Hanington, et al., 2010) it is not easy for the $S$. mansoni intramolluscan stage parasite that is not directly accessible. To avoid this problem, in vitro culture is often used in this model to obtain pure parasites and/or secretion products to identify the molecules involved in host-parasite interplay (Bender, et al., 2002, Coppin, et al., 2003, Guillou, et al., 2007, Roger, et al., 2008), to perform pharmacological investigations (Mattos, et al., 2006), or to study parasite development (Azzi, et al., 2009). However, miracidia to sporocyst in vitro transformation can be achieved only for a short period of time. For a longer period an artificial snail environment must be used involving sporocysts cocultured with Biomphalaria glabrata embryonic cells (Bge cell line) (Coustau and Yoshino, 2000, Taft, et al., 2009, Vermeire, et al., 2004). These approaches has been used with great 
success in the past, however, the in-vivo response of the parasite to the authentic host snail environment was never investigated.

Here we describe a new efficient method for improved DNA and RNA extraction from the S. mansoni intra molluscan stage. We show that the method can be used for PCR amplification, analysis of gene expression and microsatellite genotyping approaches.

\section{Material and Methods}

\subsection{Biological material, Raillet-Henry fixation and parasite recovery}

Schistosoma mansoni (Guadeloupean strain) was maintained in its sympatric Biomphalaria glabrata strain and in hamsters (Mesocricetus auratus), as described previously (Théron, et al., 1997). Miracidia were hatched from eggs recovered from 60-day-infected hamster livers. The livers were homogenized and the eggs were filtered out, washed, and transferred to spring water. The miracidia were allowed to hatch under exposure to artificial light. For each experiment, snails (7-9 $\mathrm{mm}$ in diameter) were exposed individually to 20 miracidia. For primary sporocysts (SpI) detection and recovery, the snails were fixed 15 days post-exposure, according to a modified method, previously described (Mone, et al., 2010, Theron and Gerard, 1994). In brief, each infected snail was relaxed in pond water containing an excess of crystalline menthol for $6 \mathrm{~h}$ (menthol relaxation help in shell removing and snail anatomic observation), the snail body was recovered and fixed in modified Raillet-Henry's solution ( $0.6 \% \mathrm{NaCl} ; 2 \%$ acetic acid; $2 \%$ formalin). After 24 hours in fixative, a dissection of the head-foot zone was performed, and SpIs (Figure 1) were recovered, washed two times in Phosphate Buffer Saline (PBS) for 15 min on ice and kept at $-80^{\circ} \mathrm{C}$ until use.

An alternative procedure can be used with a rapid fixation procedure when studying gene transcription. Infected snails were snap-frozen in liquid nitrogen and fixed directly with the 
shell in modified Raillet-Henry's solution ( $0.6 \% \mathrm{NaCl}$; $2 \%$ acetic acid; $2 \%$ formalin). After 24 hours in fixative, the shell is removed and SpI recovery was performed as above.

\subsection{DNA and RNA extraction and reverse transcription}

Genomic DNA (gDNA) was extracted from single Raillet-Henry fixed S. mansoni sporocysts according to the following protocol. Sixty $\mu \mathrm{l}$ of TE (Tris 10mM; EDTA 1mM; ph 8) containing $1.67 \mathrm{mg} / \mathrm{ml}$ of Proteinase K (Merck) was added to the SpI. Samples were put 3 hours at $55^{\circ} \mathrm{C}$ and vortexed each $15 \mathrm{~min}$. Then samples were heated $10 \mathrm{~min}$ at $100^{\circ} \mathrm{C}$ for proteinase $\mathrm{K}$ inactivation. gDNA were kept at $-20^{\circ} \mathrm{C}$ until use.

Total RNA was isolated from single or pool of 5 SpIs using the High Pure FFPE RNA microkit (Roche) according to manufacturer recommendations. Reverse transcription was performed using random hexamer primer and the RevertAid H minus First Strand cDNA Synthesis kit (Fermentas) following the manufacturer's protocol. cDNA were kept at $-80^{\circ} \mathrm{C}$ until use. It as been largely documented that these new extraction methods have been now optimized for RNA extraction from formalin-fixed tissue to achieve high quality microarray and qRT-PCR downstream applications (April, et al., 2009, Ribeiro-Silva, et al., 2007, Serinsoz, et al., 2005).

\subsection{PCR amplifications of $g D N A$ and $c D N A$}

gDNA PCR amplifications of fixed S. mansoni sporocyst were performed with the Advantage 2 PCR Enzyme System (Clontech). To test PCR on gDNA as template, the SmPoMuc loci (Roger, et al., 2008, Roger, et al., 2008, Roger, et al., 2008) were amplified using specific primers designed to amplify specific fragment lengths (see Table 1 for primer sequences and PCR cycling conditions). PCR conditions were: $0.5 \mu \mathrm{M}$ primers; $1 \mathrm{X}$ final Advantage 2 PCR 
112 buffer (2mM MgCl2); 0.4mM dNTPs; $1 \mathrm{X}$ final Advantage 2 polymerase and $5 \mu \mathrm{l}$ of gDNA in

113 a total volume of $20 \mu \mathrm{l}$ of RNase, DNase free water.

114 cDNA PCR amplification of fixed S. mansoni sporocyst was performed with the GoTaq 115 hotstart Enzyme (Promega). Five genes were tested (see Table 2 for gene name, primer 116 sequences and PCR cycling conditions). PCR mix was: $0.4 \mu \mathrm{M}$ primers; $1.5 \mathrm{mM} \mathrm{MgCl}$; $1170.2 \mathrm{mM}$ dNTPs, 1 unit GoTaq hot-start and $1 \mu \mathrm{l}$ of cDNA in a total volume of $20 \mu \mathrm{l}$ of RNase, 118 DNase free water. All PCR products were separated by electrophoresis through 1\% agarose 119 gels, and visualized by staining with ethidium bromide.

\subsection{PCR amplification of microsatellite loci}

122 Fifteen microsatellite markers, SmC1, SmDO11, SmDA28 (Curtis, et al., 2001), R95529,

123 SmD57, SmD28, SmD25, SCMSMOXII, L46951 (Durand, et al., 2000), SmBR16, SmBR10,

124 SmBR13 (Rodrigues, et al., 2007), SmS7-1 (Blair, et al., 2001), SmBR1, SmBR6 (Rodrigues,

125 et al., 2002) were used in this study (Table 3). The relevant DNA fragments were amplified 126 using PCR. Details on microsatellite sequences, primers and PCR conditions are available in 127 Table 3. To maximise efficiency and minimize costs, these PCRs were performed in three 128 multiplex reactions using the QIAGEN multiplex kit. The PCR amplifications of loci: 129 R95529, SmC1, SmDO11, SmBR16 and SmD57 were grouped in the multiplex 1 (M1); loci: 130 SmDA28, SmBR1, SmS7-1, SmD28, SCMSMOXII were grouped in the multiplex 2 (M2); 131 and loci: SmD25, L46951, SmBR6, SmBR10 and SmBR13 were grouped in the multiplex 3 132 (M3). These multiplex reactions were carried out according to the manufacturer's standard 133 microsatellite amplification protocol in a final volume of $10 \mu \mathrm{L}$ and with $57^{\circ} \mathrm{C}$ as annealing temperature. PCR products were diluted in Sample Loading Solution (Beckman Coulter) with 135 red-labelled size standard (CEQ ${ }^{\mathrm{TM}}$ DNA size standard kit, 400, Beckman Coulter) and 136 electrophoresis was done on an automatic sequencer (CEQ ${ }^{\mathrm{TM}}$ 8000, Beckman Coulter). 
137 Microsatellite sizes were determined using the fragment analyzer package of Beckman

138 Coulter. To confirm that the fixation procedure did not modify the microsatellite length and 139 thus did not affect negatively microsatellite analyses, we used a clonal strain of S. mansoni

140 (Brazilian strain selected for locus homozygosis) to compare the microsatellite profile

141 between fixed and non-fixed material. These samples were processed as described above.

\section{$143 \quad$ 2.5. Ethical Statements}

144 Our laboratory has received the permit \# A66040 for experiments on animals from both the

145 French Ministry of Agriculture and Fishing and the French Ministry of National Education, 146 Research and Technology. Housing, breeding and animal care of the hamster followed the

147 ethical requirements of the French government. The experimenter possesses the official 148 certificate for animal experimentation delivered by both ministries (Décret \# 87-848 du 19 149 octobre 1987).

\section{Results}

\subsection{Sporocysts detection and dissection.}

After 24 hours in Raillet-Henry fixation, SpIs are readily observable as translucent white bodies within an opaque grey tissue background (Figure 1A). At higher magnifications we could see the spherical aspect of SpI (Figure $1 \mathbf{B}$ and $\mathbf{C}$ ). Figure 1 shows a snail at 15 DPI.

157 SpIs were at their optimal development (filled with secondary sporocysts (SpIIs)), the biggest

158 reached $1 \mathrm{~mm}$ in diameter and could be recovered by careful dissection of the snail head-foot 159 zone under a binocular microscope. Dissecting SpIs before 6 DPI remains very difficult. It is 160 important to recover the SpI without taking snail tissue in order to enrich the parasite signal 161 for genomic DNA or transcript RNA extractions. 
163 3.2. S. mansoni sporocysts fixation and genomic DNA amplification

164 We tested the possibility to amplify gDNA of single SpI after Raillet-Henry fixation. PCR 165 products of up to $2 \mathrm{~kb}$ in length could be amplified from gDNA (columns 1, 2, 3; Figure 2). 166 At 2.5 and $3 \mathrm{~kb}$ amplification did not work anymore or only occasionally for some individuals

167 (see individual of column 3 at 2.5kb, Figure 2). The results were compared to a positive 168 control (classical gDNA extraction) for which PCR amplifications worked for up to $3 \mathrm{~kb}$ 169 (column 4; Figure 2). To achieve this fragment length specific amplification, we design 170 primers for SmPoMuc genes for Schistosoma mansoni polymorphic mucins. These mucins 171 were specific of S. mansoni and no related genes were present in the snail host B. glabrata, 172 thus no cross-amplifications did occur (data not showed).

173

174

175

176

177

\subsection{S. mansoni sporocysts fixation and microsatellite amplification}

Microsatellite PCR on DNA extracted from Raillet-Henry fixed SpIs shown good results (Figure 3). All microsatellite loci were amplified and fragment lengths were in agreement with the expected sizes (see Figure 3 and Table 3) based on previous studies done on DNA extracted from adults of the same parasite strain (Bech, et al., 2010, Durand, et al., 2000). In addition using a clonal strain of $S$. mansoni without microsatellite diversity we showed that microsatellite profiles were the same for fixed and non-fixed material (Table 4). The fixation procedure did not modify the microsatellite length and thus did not affect negatively microsatellite analyses.

\subsection{S. mansoni sporocysts fixation and reverse-transcription PCR.}

Five genes were selected to study the sensitivity of transcript amplification, (i) alpha tubulin is a highly expressed gene involved in microtubules (one of the main components of the 
cytoskeleton) bio-synthesis, (ii) two genes involved in different metabolic pathways, the superoxide dismutase (SOD) that is part of the antioxidant defence against reactive oxygen species and the glyceraldehyde-3-phosphate dehydrogenase (GAPDH) involved mainly in glycolysis pathway ; (iii) calreticulin is a multifunctional calcium binding protein encoded by a single copy gene in S. mansoni genome (Berriman, et al., 2009). Finally (iv) the S. mansoni antigen 10-3, a developmentally regulated surface antigen known to be expressed specifically

193 in cercaria, male and female worms, was tested. Transcript amplifications were tested for these five genes after menthol anaesthesia and Raillet-Henry fixation or after snail were snapfrozen in liquid nitrogen and Raillet-Henry fixation and the same results were obtained for both techniques. For the four first tested genes, PCR products could be obtained when 5 SpI were used for cDNA preparation (Column 1, Figure 4). cDNA extracted from a single fixed

198 SpI gave only an amplification for alpha-tubulin (Column 2, Figure 4) probably due to the greater amount of transcript for this highly expressed gene. PCR amplifications were highly specific as no cross amplifications with the intermediate host B. glabrata cDNA could be observed (Column 4, Figure 4). All those four genes were known to be expressed in miracidia and sporocysts of S. mansoni. Antigen 10-3 known not to be expressed was also tested as an internal control and as expected gave no amplifications (Figure 4).

\section{Discussion}

Identification of S. mansoni sporocyst intramolluscan stage using Raillet-Henry fixation is a classical technique used mainly to investigate prevalence and intensity or intramolluscan

208 development of the larval stages in the S. mansoni / B. glabrata model (Sire, et al., 1998, 209 Théron, et al., 1997, Theron, et al., 1998). However, recovery of these intramolluscan fixed parasite stages for extraction of DNA or RNA was never described. Indeed, study of genetic

211 information in formalin-fixed tissues is often hampered by the impossibility to amplify the 
desired DNA or RNA as a consequence of nucleic acid damage (Zimmermann, et al., 2008).

213 It is thus important to dissect snails and to recover the parasites after a short period of fixation

214 (less than 24 hours). Studying genomic or transcriptomic information of these fixed 215 intramolluscan stages will be of interest in many fields of research including the molecular 216 dialogue between parasite and the host's immune system, distribution of infrapopulation 217 genotypes or gene expression during development and maturation from SpIs to cercariae. The 218 present work describes an improved technique for DNA and RNA extraction from such 219 samples and delivers proof for their use for the study of genomic DNA, transcript expression 220 or microsatellite genotyping.

221 Raillet-Henry fixation permits to recover SpIs that are more than 6 days old. To isolate SpIs 222 before 6 DPI was quite impossible due to the minute size of these parasites at these steps. The 223 use of this technique to study post-miracidial stage or SpI within the first days of infection 224 remains therefore difficult. This constitutes the main limitation of this approach. However 225 recovery of SpIIs or cercariae is feasible (data not shown). Our extraction protocols are 226 efficient on SpIs but also on all other intramolluscan parasite stages (data not shown).

227 However for gDNA a limited size of PCR amplification exists. Apparently, Raillet-Henry 228 fixation results in gDNA breaks at around $2 \mathrm{~kb}$ because amplification of fragment of $2.5 \mathrm{~kb}$ 229 was difficult and of 3kb was impossible. Fragmentations in DNA extracted from formalin 230 preserved samples has been described before and is based on nicks and double-strand breaks 231 (Zimmermann, et al., 2008). Amplifications of microsatellite fragments of less than 500 232 nucleotides worked very well using our protocols. There is no difference in microsatellite 233 amplification between fixed and non-fixed material. Raillet-Henry fixation did not affect 234 negatively the microsatellite analyses. The technique will allow for genotyping of single 235 parasite intramolluscan stages and thus could permit reconstruction of the population structure 236 of sporocyst infra-populations inside the snail. Finally, RNA extraction and RT-PCR showed 
237 good results, cDNA transcript amplification from Raillet-Henry fixed material with or without 238 nitrogen freezing works well. In our model this will facilitate the study of gene expression for 239 all intra-molluscan parasite developmental stages at 6 DPI and older.

240 We hope that the technique developed herein paves the way to a better understanding of the 241 host/parasite molecular dialogue by taking into account more easily an often neglected partner 242 in this interaction, the parasite.

\section{Acknowledgments}

245 We are grateful to Bernard Dejean and Anne Rognon for technical assistance. We thank 246 Julien Portela for helping with picture taking. We gratefully acknowledge Dr. C. Grunau for 247 correcting the English version of this paper and for his critical reading of the manuscript. The 248 work received funding from the BiomGenIm (ANR-07-BLAN-0214-03) programs of the 249 French National Agency for Research, CNRS, and UPVD. The funding agency had no role in 250 the study design, data collection, data analysis, the decision to publish, or the manuscript 251 preparation. 
1. Adema, C. M., Hanington, P. C., Lun, C. M., Rosenberg, G. H., Aragon, A. D., Stout,

2. April, C., Klotzle, B., Royce, T., Wickham-Garcia, E., Boyaniwsky, T., Izzo, J., Cox, B. A., Lennard Richard, M. L., Gross, P. S., and Loker, E. S., 2010. Differential transcriptomic responses of Biomphalaria glabrata (Gastropoda, Mollusca) to bacteria and metazoan parasites, Schistosoma mansoni and Echinostoma paraensei (Digenea, Platyhelminthes). Molecular immunology 47, 849-860.

D., Jones, W., Rubio, R., Holton, K., Matulonis, U., Quackenbush, J., and Fan, J. B., 2009. Whole-genome gene expression profiling of formalin-fixed, paraffin-embedded tissue samples. PloS one 4, e8162.

3. Azzi, A., Cosseau, C., and Grunau, C., 2009. Schistosoma mansoni: developmental arrest of miracidia treated with histone deacetylase inhibitors. Experimental parasitology 121, 288-291.

4. Baeza Garcia, A., Pierce, R. J., Gourbal, B., Werkmeister, E., Colinet, D., Reichhart, J. M., Dissous, C., and Coustau, C., 2010. Involvement of the cytokine MIF in the snail host immune response to the parasite Schistosoma mansoni. PLoS pathogens 6.

5. Bech, N., Beltran, S., Portela, J., Rognon, A., Allienne, J. F., Boissier, J., and Theron, A., 2010. Follow-up of the genetic diversity and snail infectivity of a Schistosoma mansoni strain from field to laboratory. Infection Genetic and Evolution 10, 10391045.

6. Bender, R. C., Bixler, L. M., Lerner, J. P., and Bayne, C. J., 2002. Schistosoma mansoni sporocysts in culture: host plasma hemoglobin contributes to in vitro oxidative stress. Journal of parasitology 88, 14-18.

7. Berriman, M., Haas, B. J., LoVerde, P. T., Wilson, R. A., Dillon, G. P., Cerqueira, G. C., Mashiyama, S. T., Al-Lazikani, B., Andrade, L. F., Ashton, P. D., Aslett, M. A., Bartholomeu, D. C., Blandin, G., Caffrey, C. R., Coghlan, A., Coulson, R., Day, T. A., Delcher, A., DeMarco, R., Djikeng, A., Eyre, T., Gamble, J. A., Ghedin, E., Gu, Y., Hertz-Fowler, C., Hirai, H., Hirai, Y., Houston, R., Ivens, A., Johnston, D. A., Lacerda, D., Macedo, C. D., McVeigh, P., Ning, Z., Oliveira, G., Overington, J. P., Parkhill, J., Pertea, M., Pierce, R. J., Protasio, A. V., Quail, M. A., Rajandream, M. A., Rogers, J., Sajid, M., Salzberg, S. L., Stanke, M., Tivey, A. R., White, O., Williams, D. L., Wortman, J., Wu, W., Zamanian, M., Zerlotini, A., Fraser-Liggett, C. M., Barrell, B. G., and El-Sayed, N. M., 2009. The genome of the blood fluke Schistosoma mansoni. Nature 460, 352-358.

8. Blair, L., Webster, J. P., and Barker, G. C., 2001. Isolation and caracterization of polymorphic microsatellite markers in Schistosoma mansoni from Africa. . Molecular Ecology Notes 1, 93-95.

9. Chitsulo, L., Loverde, P., and Engels, D., 2004. Schistosomiasis. Nature reviews Microbiology 2, 12-13.

10. Coppin, J. F., Lefebvre, C., Caby, S., Cocquerelle, C., Vicogne, J., Coustau, C., and Dissous, C., 2003. Gene expression changes in Schistosoma mansoni sporocysts induced by Biomphalaria glabrata embryonic cells. Parasitology research 89, 113-119.

11. Coustau, C., and Yoshino, T. P., 2000. Flukes without snails: advances in the in vitro cultivation of intramolluscan stages of trematodes. Experimental parasitology 94, 6266.

12. Curtis, J., Sorensen, R. E., Page, L. K., and Minchella, D. J., 2001. Microsatellite loci in the human blood fluke Schistosoma mansoni and their utility for other schistosome species. Molecular Ecology Notes 1, 143-145. 
13. Durand, P., Sire, C., and Theron, A., 2000. Isolation of microsatellite markers in the digenetic trematode Schistosoma mansoni from Guadeloupe island. Molecular ecology 9, 997-998.

14. Gryseels, B., Polman, K., Clerinx, J., and Kestens, L., 2006. Human schistosomiasis. Lancet 368, 1106-1118.

15. Guillou, F., Mitta, G., Galinier, R., and Coustau, C., 2007. Identification and expression of gene transcripts generated during an anti-parasitic response in Biomphalaria glabrata. Developmental and comparative immunology 31, 657-671.

16. Guillou, F., Roger, E., Mone, Y., Rognon, A., Grunau, C., Theron, A., Mitta, G., Coustau, C., and Gourbal, B. E., 2007. Excretory-secretory proteome of larval Schistosoma mansoni and Echinostoma caproni, two parasites of Biomphalaria glabrata. Molecular and biochemical parasitology 155, 45-56.

17. Hanington, P. C., Lun, C. M., Adema, C. M., and Loker, E. S., 2010. Time series analysis of the transcriptional responses of Biomphalaria glabrata throughout the course of intramolluscan development of Schistosoma mansoni and Echinostoma paraensei. International journal for parasitology 40, 819-831.

18. Lockyer, A. E., Spinks, J., Kane, R. A., Hoffmann, K. F., Fitzpatrick, J. M., Rollinson, D., Noble, L. R., and Jones, C. S., 2008. Biomphalaria glabrata transcriptome: cDNA microarray profiling identifies resistant- and susceptible-specific gene expression in haemocytes from snail strains exposed to Schistosoma mansoni. BMC genomics 9, 634.

19. Mattos, A. C., Kusel, J. R., Pimenta, P. F., and Coelho, P. M., 2006. Activity of praziquantel on in vitro transformed Schistosoma mansoni sporocysts. Memorias do Instituto Oswaldo Cruz 101 Suppl 1, 283-287.

20. Mone, Y., Gourbal, B., Duval, D., Du Pasquier, L., Kieffer-Jaquinod, S., and Mitta, G., 2010. A large repertoire of parasite epitopes matched by a large repertoire of host immune receptors in an invertebrate host/parasite model. PLoS neglected tropical diseases 4.

21. Mone, Y., Mitta, G., Duval, D., and Gourbal, B. E., 2010. Effect of amphotericin B on the infection success of Schistosoma mansoni in Biomphalaria glabrata. Experimental parasitology 125, 70-75.

22. Ribeiro-Silva, A., Zhang, H., and Jeffrey, S. S., 2007. RNA extraction from ten year old formalin-fixed paraffin-embedded breast cancer samples: a comparison of column purification and magnetic bead-based technologies. BMC molecular biology 8, 118 .

23. Rodrigues, N. B., Loverde, P. T., Romanha, A. J., and Oliveira, G., 2002. Characterization of new Schistosoma mansoni microsatellite loci in sequences obtained from public DNA databases and microsatellite enriched genomic libraries. Memorias do Instituto Oswaldo Cruz 97 Suppl 1, 71-75.

24. Rodrigues, N. B., Silvia, M. R., Pucci, M. M., Minchella, D. J., Sorensen, R., Loverde, P. T., Romanha, A. J., and Oliveira, G., 2007. Microsatellite-enriched genomic libraries as a source of polymorphic loci for Schistosoma mansoni. Molecular Ecology Notes 7, 263-265.

25. Roger, E., Gourbal, B., Grunau, C., Pierce, R. J., Galinier, R., and Mitta, G., 2008. Expression analysis of highly polymorphic mucin proteins (Sm PoMuc) from the parasite Schistosoma mansoni. Molecular and biochemical parasitology 157, 217-227.

26. Roger, E., Grunau, C., Pierce, R. J., Hirai, H., Gourbal, B., Galinier, R., Emans, R., Cesari, I. M., Cosseau, C., and Mitta, G., 2008. Controlled chaos of polymorphic mucins in a metazoan parasite (Schistosoma mansoni) interacting with its invertebrate host (Biomphalaria glabrata). PLoS neglected tropical diseases 2, e330. 
27. Roger, E., Mitta, G., Mone, Y., Bouchut, A., Rognon, A., Grunau, C., Boissier, J., Theron, A., and Gourbal, B. E., 2008. Molecular determinants of compatibility polymorphism in the Biomphalaria glabrata/Schistosoma mansoni model: new candidates identified by a global comparative proteomics approach. Molecular and biochemical parasitology 157, 205-216.

28. Roger, E., Mitta, G., Mone, Y., Bouchut, A., Rognon, A., Grunau, C., Boissier, J., Theron, A., and Gourbal, B. E., 2008. Molecular determinants of compatibility polymorphism in the Biomphalaria glabrata/Schistosoma mansoni model: new candidates identified by a global comparative proteomics approach. Molecular and biochemical parasitology 157, 205-216.

29. Serinsoz, E., Bock, O., Kirsch, T., Haller, H., Lehmann, U., Kreipe, H., and Mengel, M., 2005. Compartment-specific quantitative gene expression analysis after laser microdissection from archival renal allograft biopsies. Clinical nephrology 63, 193201.

30. Sire, C., Rognon, A., and Theron, A., 1998. Failure of Schistosoma mansoni to reinfect Biomphalaria glabrata snails: acquired humoral resistance or intra-specific larval antagonism? Parasitology 117 ( Pt 2), 117-122.

31. Taft, A. S., Vermeire, J. J., Bernier, J., Birkeland, S. R., Cipriano, M. J., Papa, A. R., McArthur, A. G., and Yoshino, T. P., 2009. Transcriptome analysis of Schistosoma mansoni larval development using serial analysis of gene expression (SAGE). Parasitology 136, 469-485.

32. Theron, A., and Gerard, C., 1994. Development of accessory sexual organs in Biomphalaria glabrata as related to infection timing by Schistosoma mansoni: Consequences on the energy utilisation patterns by the parasite. Journal of Molluscan Studies 60, 23-31.

33. Théron, A., Pages, J. R., and Rognon, A., 1997. Schistosoma mansoni: distribution patterns of miracidia among Biomphalaria glabrata snail as related to host susceptibility and sporocyst regulatory processes. Experimental parasitology 85, 1-9.

34. Theron, A., Rognon, A., and Pages, J. R., 1998. Host choice by larval parasites: a study of Biomphalaria glabrata snails and Schistosoma mansoni miracidia related to host size. Parasitology research 84, 727-732.

35. Vermeire, J. J., Boyle, J. P., and Yoshino, T. P., 2004. Differential gene expression and the effects of Biomphalaria glabrata embryonic (Bge) cell factors during larval Schistosoma mansoni development. Molecular and biochemical parasitology 135, 153-157.

36. WHO, 2002. TDR Strategic Direction for Research: Schistosomiasis. World Health Organization Information.

37. Zimmermann, J., Hajibabaei, M., Blackburn, D. C., Hanken, J., Cantin, E., Posfai, J., and Evans, T. C., Jr., 2008. DNA damage in preserved specimens and tissue samples: a molecular assessment. Frontiers in zoology 5, 18. 
Table 1: Primers used for genomic DNA PCR

\begin{tabular}{|c|c|c|c|c|c|}
\hline $\begin{array}{l}\text { Fragment } \\
\text { length }\end{array}$ & $\begin{array}{l}\text { Forward } \\
\text { primer name }\end{array}$ & Forward primer sequence & $\begin{array}{l}\text { Reverse } \\
\text { primer } \\
\text { name } \\
\end{array}$ & Reverse primer sequence & Cycling conditions \\
\hline 1010 bp & Exon6F & TGAAGCTCAACTCAGTAAGCTGAAC & Exon5R & CTTGTATCGCCTTCGATTCCAATTC & Ta: $58^{\circ} \mathrm{C}$ - elong: $68^{\circ} \mathrm{C}, 3 \mathrm{mi}$ \\
\hline 1422 bp & 10483ex13.F2 & ACGAGGATTAATGATTACAAATATGC & Exon11R & TAGATAATGTACTGCCCACTTTGTG & Ta: $58^{\circ} \mathrm{C}$ - elong: $68^{\circ} \mathrm{C}, 3 \min 30-40$ cycles \\
\hline 1999 bp & InTron14/15.F & CACTTGTTCATAAACACGTGTCTTC & Exon11R & TAGATAATGTACTGCCCACTTTGTG & Ta: $58^{\circ} \mathrm{C}$ - elong: $68^{\circ} \mathrm{C}, 3 \min 30$ - 40 cycles \\
\hline 2517 bp & Exon11F & ATTTCTTCTAGAATGTCTGAG & InTron6/7.R & TAAAGGTGGAATATGCCAAACTCAC & Ta: $58^{\circ} \mathrm{C}$ - elong: $68^{\circ} \mathrm{C}, 3 \min 30-40$ cycles \\
\hline 3052 bp & InT3/4-3.3.F & CTATGGACACTATGAACAATATTCG & InTron6/7.R & TAAAGGTGGAATATGCCAAACTCAC & Ta: $58^{\circ} \mathrm{C}$ - elong: $68^{\circ} \mathrm{C}, 3 \min 30-40$ cycles \\
\hline
\end{tabular}

bp: base pairs

Ta: Primers annealing temperature in centigrade; elong: temperature in centigrade and duration of elongation in minutes. 
Table 2: Primers used for cDNA PCR

\begin{tabular}{|c|c|c|c|c|}
\hline Gene name & Accession No. & Forward primer & Reverse primer & Cycling conditions \\
\hline Alpha tubulin & SCMSAT1A & AGCAGTTAAGCGTTGCAGAAATCA & TGACGAGGGTCACATTTCACCAT & Ta: $53^{\circ} \mathrm{C}$ - elong: $72^{\circ} \mathrm{C}, 30$ sec -40 cycles \\
\hline $\begin{array}{l}\text { Superoxide dismutase } \mathrm{Cu} / \mathrm{Zn} \\
\text { (SOD) }\end{array}$ & XM_002580438 & AGTGGACTCAAGGCTG & CCACGGCCTAAATCAT & Ta: $54^{\circ} \mathrm{C}$ - elong: $72^{\circ} \mathrm{C}, 30$ sec -40 cycles \\
\hline $\begin{array}{l}\text { Glyceraldehydes-3-phosphate } \\
\text { dehydrogenase (GAPDH) }\end{array}$ & XM_002576947 & GCGAGGTTTCGACTGA & AACAACGAACATGGGTG & Ta: $55^{\circ} \mathrm{C}$ - elong: $72^{\circ} \mathrm{C}, 30$ sec -40 cycles \\
\hline Calreticulin & XM_002574439 & ATACGCTCTGGGACAT & CCTTGCTTCTCGGCATTA & Ta: $54^{\circ} \mathrm{C}$ - elong: $72^{\circ} \mathrm{C}, 30$ sec -40 cycles \\
\hline S.mansoni antigen 10-3 (Ag10-3) & M22346.1 & CACAAGGGTCTACTGCTAACGGA & CСTTTAACATGGAATTTATCAGTCTGG & Ta: $54^{\circ} \mathrm{C}$ - elong: $72^{\circ} \mathrm{C}, 30$ sec -40 cycles \\
\hline
\end{tabular}

Ta: Primer annealing temperature in centigrade; elong: temperature in centigrade and duration of elongation in seconds.

GenBank Accession numbers (No.) are indicated. 
Table 3: Primers used for Microsatellite PCR

\begin{tabular}{|c|c|c|c|c|c|c|c|}
\hline Multiplex & $\begin{array}{l}\text { Microsatellite } \\
\text { name }\end{array}$ & $\begin{array}{l}\text { Accession } \\
\text { No. } \\
\end{array}$ & $\begin{array}{l}\begin{array}{l}\text { Range } \\
\text { size (nt) }\end{array} \\
\end{array}$ & Repeat motif & Forward sequence & Reverse sequence & Cycling conditions \\
\hline \multirow[t]{5}{*}{ M1 } & R95529 & R95529 & $228 / 275$ & $(\mathrm{CAT}) 10$ & GTGATTGGGGTGATAAAG & CATGTTTCTTCAGTGTCC & Ta: $57^{\circ} \mathrm{C}$ - elong: $72^{\circ} \mathrm{C}, 1 \mathrm{~min}-35$ cycles \\
\hline & SmC1 & AF325694 & $287-296$ & $(\mathrm{AAT}) 6-16$ & TGACGAGGTTGACCATAATTCTAC & AACACAGATAAGAGCGTCATGG & Ta: $57^{\circ} \mathrm{C}$ - elong: $72^{\circ} \mathrm{C}, 1 \mathrm{~min}$ - 35 cycles \\
\hline & SmD57 & AF202967 & $276-300$ & (TA)22(GA)9 & TCCTTGATTCCACTGTTG & GCAGTAATCCGAAAGATTAG & Ta: $57^{\circ} \mathrm{C}$ - elong: $72^{\circ} \mathrm{C}, 1 \mathrm{~min}-35$ cycles \\
\hline & SmBR16 & L04480 & $337-341$ & (TA)10 & TGTGACTTTGATGCCACTGA & GGCCTGATACAATTCTCCGA & Ta: $57^{\circ} \mathrm{C}$ - elong: $72^{\circ} \mathrm{C}, 1 \mathrm{~min}-35$ cycles \\
\hline & SmDO11 & AF325698 & 303-367 & (GATA)20-37 & TGTTTAAGTCGTCGGTGCTG & ACCCTGCCAGTTTAGCGTAG & Ta: $57^{\circ} \mathrm{C}$ - elong: $72^{\circ} \mathrm{C}, 1 \mathrm{~min}-35$ cycles \\
\hline \multirow[t]{5}{*}{ M2 } & SmDA28 & AF325695 & $91-115$ & (GATA)7-14 & CATGATCTTAGCTCAGAGAGCC & AGCCAGTATAGCGTTGATCATC & Ta: $57^{\circ} \mathrm{C}$ - elong: $72^{\circ} \mathrm{C}, 1 \mathrm{~min}$ - 35 cycles \\
\hline & SmBR1 & L81235 & 154 & $(\mathrm{AC}) 9$ & GAGTATACGGCTTCTTGGA & CGGAACGACAAGAAAATCAT & Ta: $57^{\circ} \mathrm{C}$ - elong: $72^{\circ} \mathrm{C}, 1 \mathrm{~min}$ - 35 cycles \\
\hline & SmS7-1 & AF330105 & 184 & $(\mathrm{AC}) 17$ & ТССТССТСТСТАТТTТСТСТTТG & ATTACGATTGCACAGATACTTTTG & Ta: $57^{\circ} \mathrm{C}$ - elong: $72^{\circ} \mathrm{C}, 1 \mathrm{~min}-35$ cycles \\
\hline & SmD28 & AF202966 & $240-244$ & $(\mathrm{CAA}) 5$ & САТСАССАТСААТСАСТС & TATTCACAGTAGTAGGCG & Ta: $57^{\circ} \mathrm{C}$ - elong: $72^{\circ} \mathrm{C}, 1 \mathrm{~min}-35$ cycles \\
\hline & SCMSMOXII & M85305 & 283-295 & (CAT)9CGT(CAT)6 & TTCTACAATAATACCATCAAC & TTTTTTCTCACTCATATACAC & Ta: $57^{\circ} \mathrm{C}$ - elong: $72^{\circ} \mathrm{C}, 1 \mathrm{~min}-35$ cycles \\
\hline \multirow[t]{5}{*}{ M3 } & SmBR10 & DQ448293 & $109-133$ & (GATA) 10 & CATGATCTTAGCTCAGAGAGC & GTACATTTTATGTCAGTTAGCC & Ta: $57^{\circ} \mathrm{C}$ - elong: $72^{\circ} \mathrm{C}, 1 \mathrm{~min}-35$ cycles \\
\hline & L46951 & L46951 & $168-174$ & (GAA)7 & CAAACATATACATTGAATACAG & TGAATTGATGAATGATTGAAG & Ta: $57^{\circ} \mathrm{C}$ - elong: $72^{\circ} \mathrm{C}, 1 \mathrm{~min}$ - 35 cycles \\
\hline & SmBR13 & DQ137790 & $205-225$ & (CTAT)16 & GTCACAGATACCTGACGAGCTG & ACTCCСCAGCAATTTGTCC & Ta: $57^{\circ} \mathrm{C}$ - elong: $72^{\circ} \mathrm{C}, 1 \mathrm{~min}-35$ cycles \\
\hline & SmBR6 & AF009659 & $272-278$ & (CTT)10 & CTTAACAGACATACACGC & GAATACAGGCTATAATCTACA & Ta: $57^{\circ} \mathrm{C}$ - elong: $72^{\circ} \mathrm{C}, 1 \mathrm{~min}$ - 35 cycles \\
\hline & SmD25 & AF202965 & $268-274$ & $(\mathrm{CA}) 10$ & GATTCCCAAGATTAATGCC & GCCATTAGATAATGTACGTG & Ta: $57^{\circ} \mathrm{C}$ - elong: $72^{\circ} \mathrm{C}, 1 \mathrm{~min}-35$ cycles \\
\hline
\end{tabular}

Characteristics of Schistosoma mansoni strain Guadeloupe (GUA) microsatellite loci, including locus name, GenBank Accession number (No.), size

of PCR products in nucleotides (nt), nature of repeated motifs, forward and reverse primer sequences, annealing temperature in centigrade (Ta);

elong: temperature in centigrade and duration of elongation in minutes. 
Table 4: Comparison of microsatellite sizes for fixed and non-fixed materials.

\begin{tabular}{llcc}
\hline Multiplex & Microsatellite name & Size (bp) for fixed material & Size (bp) for non-fixed material \\
\hline M1 & R95529 & 275 & 275 \\
& SmC1 & 290 & 290 \\
& SmD57 & 296 & 296 \\
& SmBR16 & 337 & 337 \\
& SmDO11 & 332 & 332 \\
\hline M2 & SmDA28 & 115 & 115 \\
& SmBR1 & 154 & 154 \\
& SmS7-1 & 184 & 184 \\
& SmD28 & 240 & 240 \\
& SCMSMOXII & 295 & 295 \\
\hline M3 & SmBR10 & 133 & 133 \\
& L46951 & 168 & 168 \\
& SmBR13 & 221 & 221 \\
& SmBR6 & 272 & 272 \\
& SmD25 & 292 & 292 \\
\hline
\end{tabular}

Microsatellite locus sizes of Schistosoma mansoni Brazilian clonal strain. 


\section{Legends to figures}

Figure 1. Visualisation of implanted SpI in snail tissue at 15DPI after Raillet-Henry fixation. The SpI were readily observable as translucent white bodies within an opaque tissue background (A). Higher magnification showing the spherical aspect of $\operatorname{SpI}(\mathbf{B}, \mathbf{C})$. Biomphalaria glabrata was exposed to 20 miracidia of Schistosoma mansoni.

Figure 2. PCR amplification of genomic DNA recovered from Raillet-Henry fixed sporocysts. Columns 1, 2 and 3 correspond to individual sporocysts fixed in Raillet-Henry. Column 4 is a PCR positive control using gDNA extracted from non fixed miracidia and column 5 correspond to the negative PCR control. Specific fragment lengths were amplified using specific primer couples designed on SmPoMuc gene (Roger, et al., 2008, Roger, et al., 2008, Roger, et al., 2008). See Table 1 for primer sequences and PCR conditions.

MW: molecular weight in kilo bases.

Figure 3. Multiplex microsatellite fragments profiles visualised after PCR amplifications and sequencing using the CEQ 8000 fragment analyzer package (Beckman Coulter). For each multiplex (M1, M2, M3) the name and size position of microsatellites were indicated (see Table 3 for primer sequences and PCR conditions). For SCMSMOXII, as the dye signal is faint compared to the others, we showed a higher magnification of this microsatellite in the upper right corner of the M2 picture.

nt: nucleotide; RFU: relative fluorescent units.

Figure 4. PCR amplification of cDNA transcripts recovered from Raillet-Henry fixed sporocysts. Column 1 corresponds to the pool of cDNA originating from 5 sporocysts fixed in 
Raillet-Henry. Column 2 corresponds to the cDNA of 1 sporocyst fixed in Raillet-Henry. Column 3 corresponds to a positive control using cDNA originating from non fixed miracidia. Column 4 corresponds to Biomphalaria glabrata cDNA. Column 5 corresponds to retrotranscription negative control. Column 6 corresponds to PCR negative control. See Table 2 for primer sequences and PCR conditions.

MW: molecular weight in base pairs. 

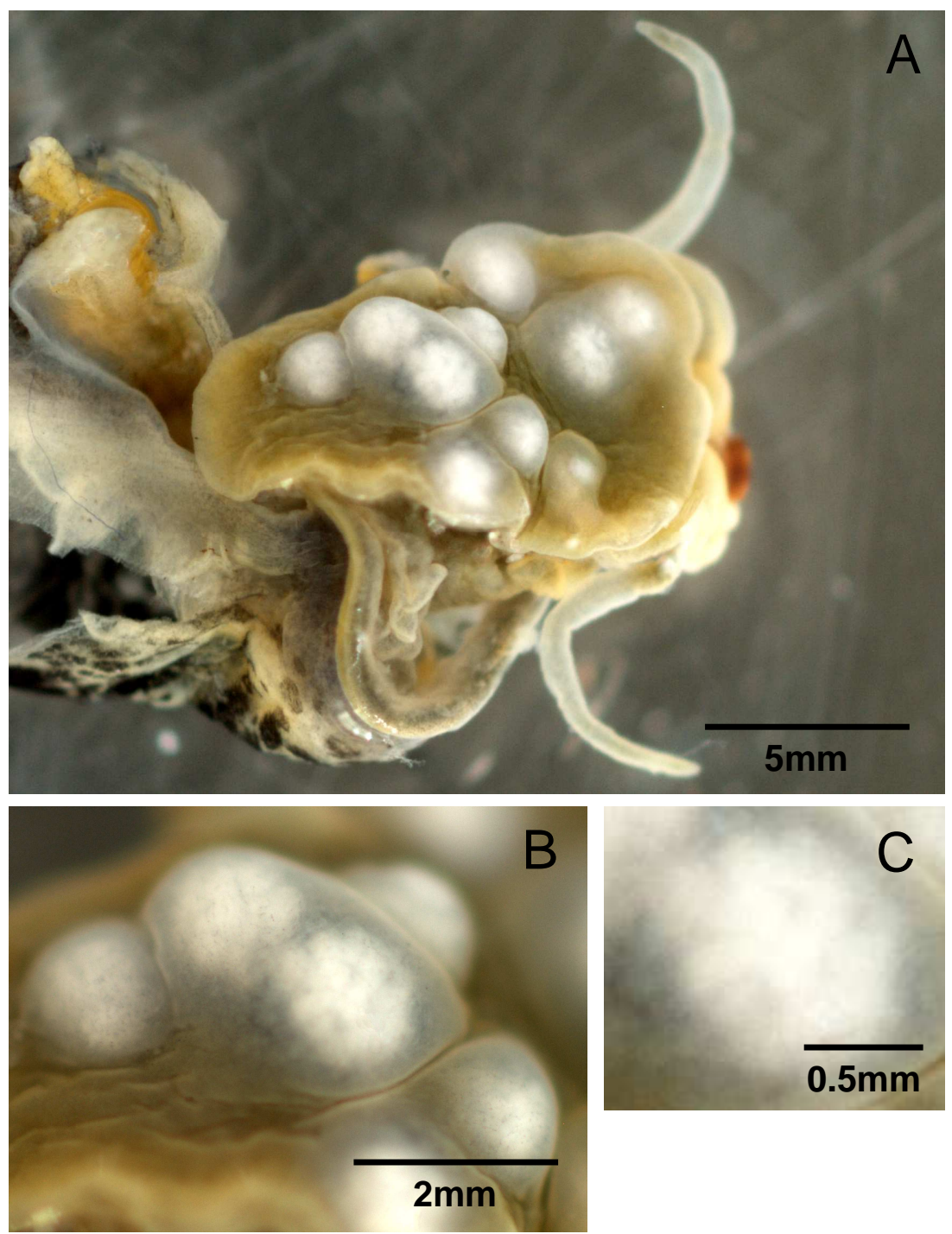


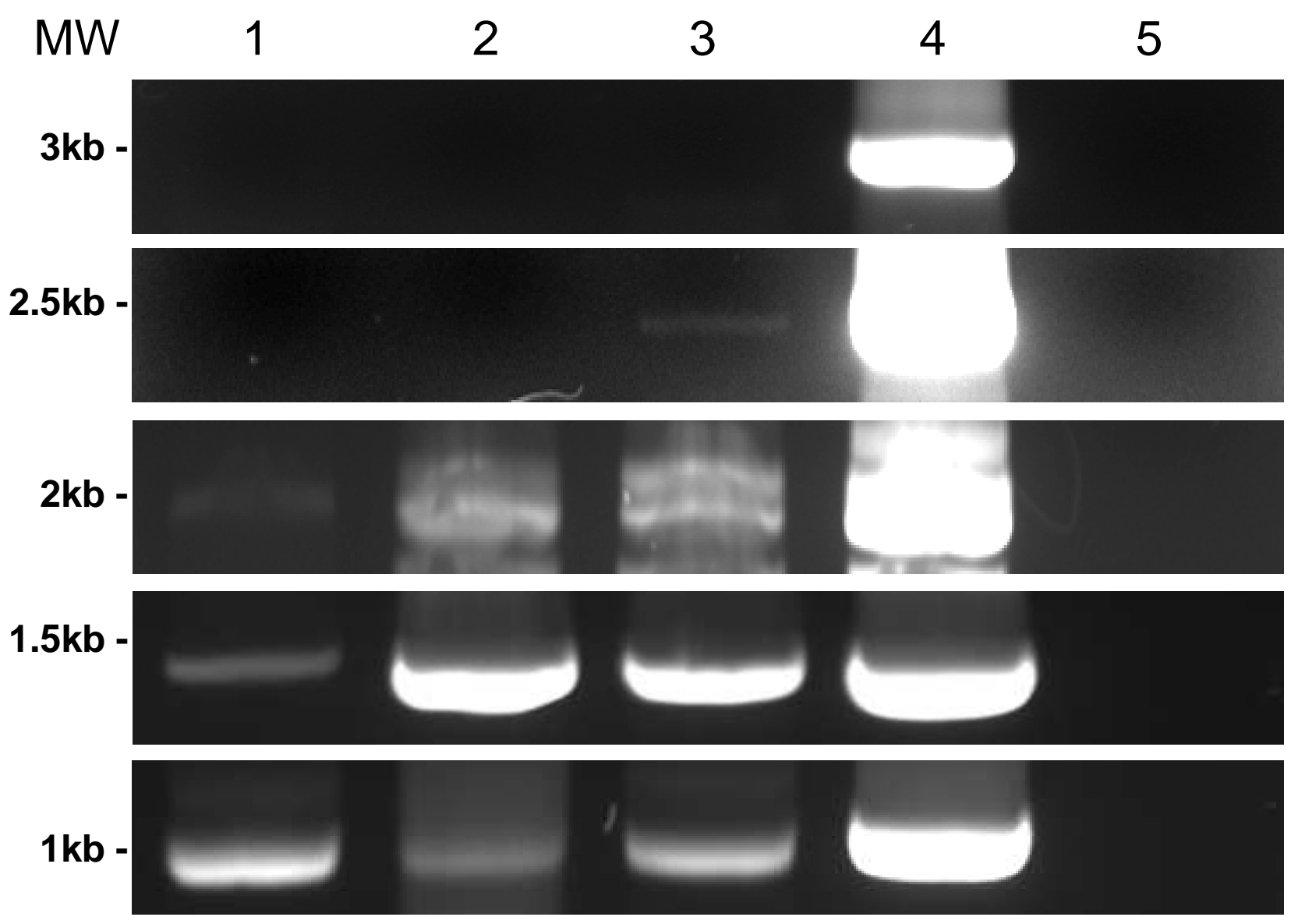



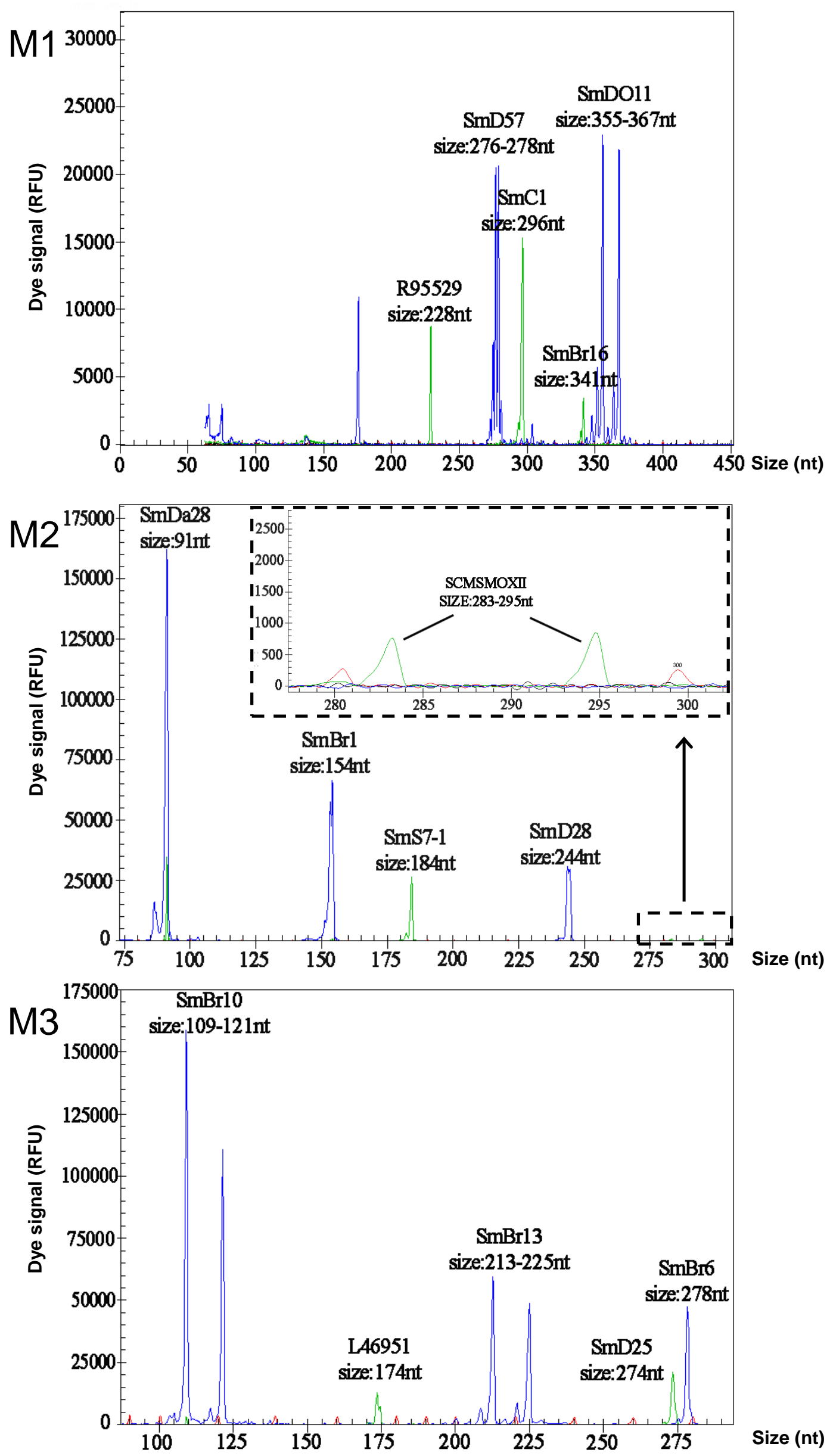


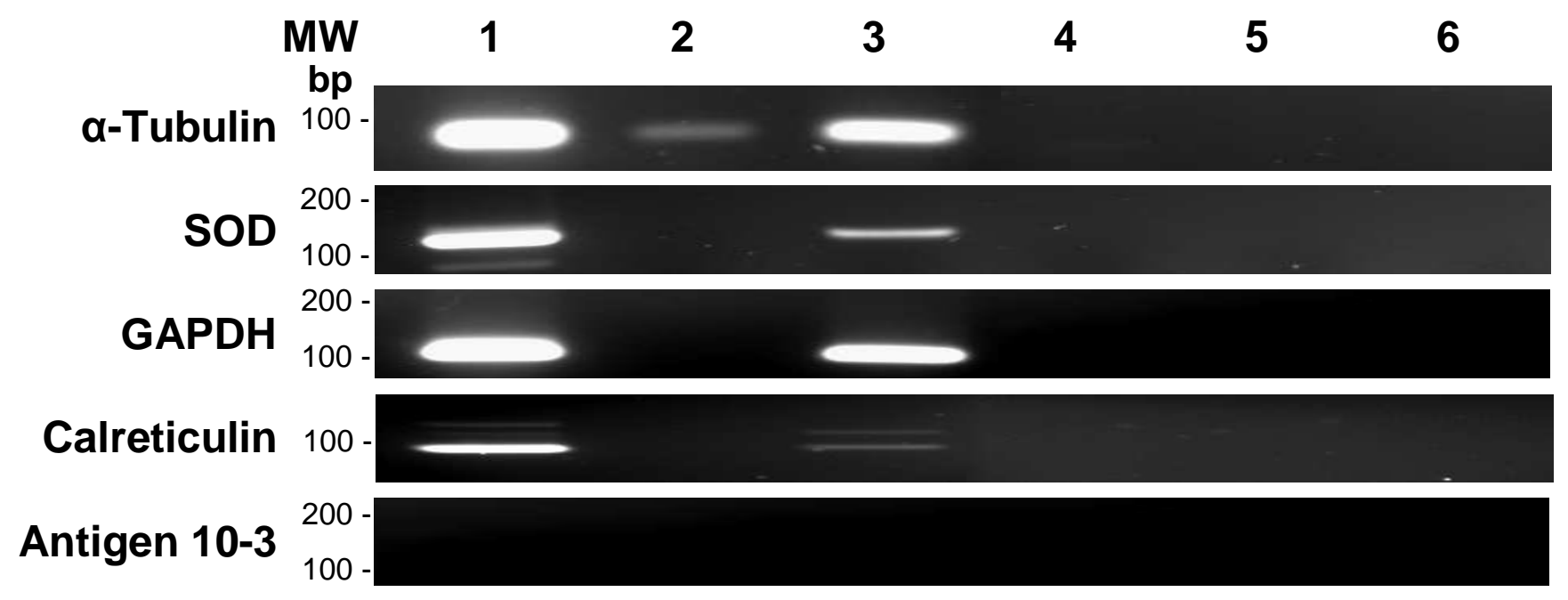

